\title{
Behavioral Changes Observed In Firstborn Child by the Parents after the Birth of Second Child in Urban Areas of Pune City
}

\author{
Shaila Mathew ${ }^{1}$, Ranjana G. Tryambake ${ }^{2}$ \\ ${ }^{1}$ Lecturer Bharati Vidyapeet College of Nursing, Sangli \\ ${ }^{2}$ Lecturer Bharati Vidyapeet College of Nursing, Pune, Maharashtra, India
}

\begin{abstract}
Study was aimed to assess the behavioral changes observed by the parents in the firstborn child after the birth of second child and to co-relate the behavioral changes with the selected demographic variables. The study was conducted in selected urban areas of Pune city. Population consists of mothers of two children. non-probability convenient Sampling technique was used.The study Consisted of 100 mothers of two children having age difference of minimum of one year and maximum of nine years. Major Findings: The observation of the mothers showed that majority of firstborn child had moderate (64\%)sibling rivalry,23\% had mild sibling rivalry and $13 \%$ had severe sibling rivalry. Conclusion: Present study reveals that when the spacing between two children is less, sibling rivalry increases.
\end{abstract}

Keywords: Behavioral changes, firstborn, child, Parents Urban Area

\section{Introduction}

"A beginning is the time for taking the most delicate care..." $[1]^{1}$

Children are gift of God, a precious treasure nurtured with love and care.

"A family cares for itself; it is a separate entity larger than each of the members. It has feelings - sadness, happiness, peaks and valleys strongly bonded with these attributes among the members[2]. ${ }^{2}$

The concept of small family norm, gaining independence it has given rise to issues of difference in opinion among the siblings who are restricted to a miniature environment.

While many kids are lucky enough to become the best of friends with their siblings, it's very common for brothers and sisters to fight. Often, sibling rivalry starts even before the second child is born, and continues as the kids grow and compete for everything from toys to attention. As kids reach different stages of development, many different things can cause siblings to fight [2]. ${ }^{2}$

Most brothers and sisters experience some degree of jealousy or competition, and this can flare into squabbles and bickering. But other factors also might influence how often the kids fight and how severe the fighting. Evolving needs, Role models, Individual temperaments and sick kids influence the way kids fight with one another[3]. ${ }^{3}$

According to Zukow, having a new baby in the family may be one of the tougher things the older child has to deal with. However it may eventually be one of the greatest gifts you can give them. Siblings act as socializing agents throughout the world" [4]. ${ }^{4}$
Another study examined the Kwuarua culture in the south Pacific islands. This study revealed how important older sibling were in giving child care, and their sibling rivalry was practically non-existent[5]. ${ }^{5}$

By "Sibling rivalry" we mean the antagonism or hostility between the brothers or sisters which manifests itself in circumstances such as in the common children's family fights which begin with a pulling of the sibling's hair or with the unwillingness to share a prized toy, which try the patience of parents all over the world. To much more serious cases such as the permanent enmity between adult siblings, eg the Biblical case of the murder of Abel by Cain.

In nature there are some extreme cases of sibling rivalry. Baby sharks develop within the mother sharkes Womb and the biggest baby shark devours his brothers and sisters, ensuring for himself all of the available food resources. The problem is basically for one of competition for limited or scarce resources. In nature, the competition is usually for food. Whenever there are two individuals or species that consume the same type of food in the same area (or habitat) they will fight with each other until one of them manages to kill or drive the other out, leaving the winner with the exclusive use of the food resources available in that area.

Many kids are lucky enough to become the best of friends with their siblings; it's very common for brothers and sisters to fight. As kids reach different stages of development, their evolving needs can significantly affect how they relate to one another.

Siblings are important and constant socializing agent in most of the children "s life [1].

Researches indicate that a child's personality has more effect on how they react to a new baby. Children with close relationships with their mothers are the most upset after the 


\section{International Journal of Science and Research (IJSR) \\ ISSN (Online): 2319-7064 \\ Index Copernicus Value (2013): 6.14 | Impact Factor (2014): 5.611}

second baby is born. Children with a close relationship with their father seem to adjust better [6].

Female -Female sibling dyads share a closer relationship than any other sibling pairs [7].

The Child's developmental stage may have an affect on how well they can share your attention. Often two-year-olds have lots of trouble getting used to a new baby, because their needs for time and closeness from their parents are great.

Our children compete for time, love, attention and approval that the parents give. The sibling relationship is often overlooked. In depth family relationship analyses, particularly amongst siblings, are left to psychologist. Therefore majority of the sibling rivalry research comes from a paradigm that is highly, parent to child ${ }^{e c}$ in nature, solely intra familial and focused on the early year.

The arrival of a new baby is stressful especially for the firstborn and for siblings between 3 and 5 years old. Regressive behaviors and aggressive behaviors such as handling the baby roughly can also occur. All of these symptoms are considered to be typical and developmentally appropriate for children between the age of 35yrs7.Regressive behavior may include demand for bottle, thumb sucking, requests to wear diapers even when toilet trained, or request to carry security blanket. Regressive behavior is the childes way of demanding the parentes love and attention' [2]

American Academy of Pediatrics suggests that instead of protesting or telling children to act according to their age, parents should simply grant their requests without becoming upset. The affected children will soon return to their normal routine when they realize that they too have an important place in the family as the new sibling. Most of the behaviors can be improved within a few months [9].

The university of Michigan Health system advices that most occurrences of regressive behaviours are mild and are to be expected. However, it recommends parents to contact a pediatrician or child psychologist if the older child tries to hurt the baby[10].

Each child in a family competes to define who they are as individuals and want to show that they are separate from their siblings. Sibling rivalry increases when children feel they are getting unequal amount of their parents attention, where there is stress in the parents and children's lives, and where fighting is accepted by the family as a way to resolve conflicts. Sigmond Freud saw the sibling relationship as an extension of the Oedipus Electra complex where brothers were in competition for their mothers attention and sisters for their fathers.

Evolutionary psychologist explain sibling rivalry in terms of parental investment and kin selection: a parent is inclined to spread resources equally among all children in the family, but a child wants most of the resources for him or herself.

Some researchers say birth order differences are as strong as gender difference. "Within the family, they are about as strong as gender differences. Frank Sulloway, in his book "Born to Rebel", he says later-borns tend to rebel because they often can't do what their older siblings can do, so they start trying to find other ways, even dangerous ones, to get their parents' attention. Younger siblings are more inclined to try these experimental, sometimes dangerous things.

One third of the children show developmental gain after the birth of a sibling. Among young siblings struggles over objects, hitting or pushing, teasing and verbal threats are measured to occur on an average of eight times per hour. The rate decreases with age. Older siblings are likely to engage in verbal antagonism. School age children have reported sibling conflict $91 \%$ of the time. $40 \%$ hit a sibling with objects. Violence acts were reported for $49 \%$ out of $68 \%$. Among adults surveyed, $71 \%$ recalled having rivalries feeling among siblings[11].

Article published by library adoption.com stated that onethird of the parents reported that the relationship between their children shifts between truce and war. Seven percent described their children as the worst enemies. Twenty-five percent admitted that relationships occasionally get meanspirited. Only one-third reported that their children were best friends [12].

Very few recommendations are made in the popular media on building sibling relationships. Researchers report parents want to know what to-do to promote warmth and closeness between siblings. While much more research is needed for preschoolers, it was found that highlighting the abilities of the child, encouraging the older child in care giving and including the children together in common activities promoted social interaction. Also, allowing "uninterrupted uncensored interaction" among school-age children and refraining from correcting or criticizing the older child"s behavior promoted closeness.

Since sibling rivalry is a common feature of the growing up years, the researcher is interested in exploring the area, which can be of prime concern in strengthening the bond between two siblings.

\section{Problem statement}

" A Study to assess the behavioral changes observed in firstborn child by the parents after the birth of second child in selected urban areas of Pune city "

\section{Objectives:}

- To assess the behavioral changes observed by the parents in the firstborn child after the birth of second child.

- To co-relate the behavioral changes with the selected demographic variables.

\section{Delimitation:}

1) Study will be limited to the parents of two children with younger child minimum of one year.

2) Study will be limited to parents of elder child up to ten years.

3) Study will be limited to urban areas of Pune city. 


\section{International Journal of Science and Research (IJSR) \\ ISSN (Online): 2319-7064}

Index Copernicus Value (2013): 6.14 | Impact Factor (2014): 5.611

\section{Research Methodology}

Research methodology involves the systematic procedure by the researcher which starts from the initial identification of programme to its final conclusion [8].

A quantitative Non -experimental exploratory survey research method was the design used for the study. It was considered to be the most suitable method as it can be used for a wide range of phenomena and it can be applied to a large number of population.

\section{Settings}

The present study was conducted in selected urban areas of Pune city .ie, Dhankawadi, Katraj and Balaji nagar.

\section{Population}

In this study the population consist of mothers of two children in selected urban areas of Pune city.

\section{Sampling Technique}

Sampling technique used in this study was non-probability convenient method of sampling. Samples were selected according to the criteria after obtaining permission from the corporators of the selected areas.

\section{Sample Size}

The study Consisted of 100 mothers of two children having age difference of minimum of one year and maximum of nine years in selected urban areas of Pune city.

\section{Inclusion Criteria}

a) Parents who can read English or marathi.

b) Child from the same parent.

c) Parents who are willing to participate.

\section{Exclusion Criteria}

a) Stepparents will be excluded.

b) Parents of critically and chronically ill child.

c) Parents of mentally unstable children.

\section{Data Collection Technique and Tool}

Research technique deals with the manner in which the data has been collected. Research tool is the means whereby data can be collected. It is the instrument that the researcher uses to enhance the process for data collection.

Based on the study objectives the self-reporting questionnaire was used. The tool was divided in to two sections. The first section contained demographic data of the mother, first born child, second child and the age difference of the two children. The second section contained 35 questions related to behavioral changes in which 26 were negative statements and 09 were positive statements. Negative statements were scored as $0,1,2$ and positive statements were scored as 2, 1, 0 .

Since it is a self reported questionnaire the total scoring was formulated by a investigator with the help of the statistician and the clinical psychologist. Therefore the total score was divided as $0-23$ as mild sibling rivalry, 24-47 as moderate sibling rivalry and $48-70$ as maximum sibling rivalry.
Validity

17 experts did the content validity of the tool. The experts were selected from various fields based on the topic ie, seven from pediatrics, three from clinical psychology, one from psychiatry; one from medical surgical, two from Gynaec and obstetric and two from community. There were some corrections were there in the content of the questionnaire which was made, and it was translated in to Marathi. Language experts established the validity of the translated tool.

\section{Reliability}

The reliability coefficient, $\mathrm{re}^{\mathrm{ee}}$ of the questionnaire was 0.92 , which is more than 0.8 , hence it was found to be reliable.

\section{Pilot Study}

The pilot study for present Research study was conducted from $28 / 07 / 2007$ to $29 / 07 / 2008$ to assess the feasibility of the study. The subjects of pilot study were excluded from the final study.10 mothers were taken for the pilot study. The investigator selected the mothers individually and explained the purpose of the study, cleared their doubts and got written consent from them for the participation of the study. The tool was given to each one and mothers were asked to fill it immediately. It was observed that, $20 \%$ were having mild sibling rivalry, $70 \%$ of the firstborn child were having moderate sibling rivalry and only $10 \%$ of firstborn child showed severe sibling rivalry as observed by the mother.

The pilot study helped the investigator to visualize some practical problems that could be faced while conducting the study and gave better insight about research methodology.

\section{Data Collection Process}

Permission was taken from the corporators of Dhankawadi, Balajinagar and Katraj areas to conduct the study. The researcher visited each family and selected the samples according to the criteria. The data gathering process began from 02/08/2008-28/08/2008. Informed consent was taken before filling the questionnaire.

\section{Findings of the Study}

\section{Section I}

Age:-It was found that $46 \%$ of mothers belonged to the age group of $31-35$ years, $25 \%$ of mothers belonged to the age group of $26-30$ years, $24 \%$ of mothers belonged to the age group of 22-25 years and 5\% of mothers belonged to the age group of 36-40 years.

Education: It was found that $31 \%$ of mothers were having higher secondary education, $30 \%$ of mothers were having higher secondary education, $20 \%$ of mothers were graduate .

Occupation: $41 \%$ of mothers were house wives, $40 \%$ are in service, $10 \%$ are doing business and $9 \%$ are doing other job.

Family income: Present study reveals that $37 \%$ were having the income of RS10001-15000 per month,28\% were having Rs 5000-10000per month,18\% were having less than Rs5000 and $17 \%$ were having more than Rs 15001 . 


\section{International Journal of Science and Research (IJSR) \\ ISSN (Online): 2319-7064}

Index Copernicus Value (2013): 6.14 | Impact Factor (2014): 5.611

Age of first born child: It was found that $70 \%$ of the first born child were in the age group of 5-8 years of age ,21\% were belonged to the age group of 9-10 years and $9 \%$ were belonged to the age group of 3-4 years.

Gender of first born child: It was found that $51 \%$ are female children and $49 \%$ are male children.

Age of second born children: It was found that $38 \%$ of second born children belonged to the age group of 3-4 years, $34 \%$ are belonged to the age group of $1-2$ years , $23 \%$ belong to the age group of 5-6 years and 5\% belong to the age group of 7-8 years.

Gender of second born child: $61 \%$ are female children, $39 \%$ are male children.

Age difference between first and second born children: $63 \%$ children are 1-3 years of age difference, $34 \%$ children are 4-6 years of age and 3\% are 7-9 years of age difference.

There was no significant co-relation between behavioral changes with selected demographic variables, except age difference between first and second born child, as the chisquare calculated value is greater than the table value. Present study reveals that when the spacing between two children is less, the degree of sibling rivalry increases.

\section{SECTION II}

Behavioral changes (sibling rivalry) observed by the mother in first born child after the birth of second child.

Self reported questionnaire was used to collect the data. The total score was 70 and was divided as 0-23 (mild sibling rivalry), $24-47$ (moderate sibling rivalry) and $48-70$ as severe sibling rivalry. It was found that majority of the first born children (64\%) were having moderate sibling rivalry, $23 \%$ are having mild sibling rivalry and $13 \%$ are having severe sibling rivalry as observed by the mother.

\section{Discussion}

A study was conducted to assess the behavioral changes in the firstborn child by the parents after the birth of second child in selected urban areas of Pune city".

Results were analyzed and were found to be consistent with the studies done earlier.

It was found that in the demographic data of age of the mother $46 \%$ of mothers belong to the age group of $31-35$ years, $25 \%$ of mothers belong to the age group of $26-30$ years $24 \%$ of mothers belong to the age group of 22-25 years and $5 \%$ of mothers belong to the age group of $36-40$ years. In education $31 \%$ of mothers were having higher secondary education, $30 \%$ of mothers were having higher secondary education, $20 \%$ of mothers were graduates and $41 \%$ of mothers were house wives, $40 \%$ were in service, $10 \%$ were doing business and 9\% were doing other job.

It was found that $70 \%$ of the first born child are in the age group of 5-8 years of age ,21\% are belong to the age group of $9-10$ years and $9 \%$ are belong to the age group of 3-4 years.
Studies conducted by child development institute shows that when the age of the first born is more the rate of fight between the siblings decreases.

In the present study $51 \%$ are female children and $49 \%$ are male children. A similar study conducted by Furman shows that there is a tendency for girls to feel more positive towards siblings than the boys.

$38 \%$ of second born children belonged to the age group of 3 4 years, $34 \%$ are belonged to the age group of $1-2$ years ,23\% belong to the age group of 5-6 years and 5\% belong to the age group of 7-8 years.

However when correlation was done regarding the age difference between two children, it was significantly correlated. $61 \%$ are female children, $39 \%$ are male children. Studies showed that with the same sex attachments are generally of higher quality than with cross sex siblings.

When the age difference was studied it was seen that $63 \%$ children had 1-3 years of age difference, 34\% children had 4 6 years of age and 3\% had 7-9 years of age difference. Several studies have shown that a wide gap promotes more social behavior but aggressive behavior were more prevalent in closely spaced children. sibling relations were more conflictual when the age gap was wider.

The present study reveled that there is no significant corelation between the behavioral changes and the selected demographic variables, except for the age difference between the first and second born child, as the chi-square calculated value was greater than the table value.

Present study revealed that when the spacing between two children was less, the degree of sibling rivalry increased.

The findings of the present study have been discussed with reference to the objectives and hypotheses. Finding of the study shows that among the behavioral changes observed by the mother in firstborn after the birth of second child were moderate sibling rivalry for $64 \%, 23 \%$ had mild sibling rivalry and $13 \%$ had severe sibling rivalry.

The study findings were consistent with the study conducted by Alfred Adler on 60 sibling which showed that $60 \%$ had minimum sibling rivalry, $29 \%$ didn't have any fight between and $3 \%$ showed the sibling rivalry which extended up to physical abuse ${ }^{18}$.

\section{Summary}

The purpose of the study was to assess the behavioral changes of firstborn child after the birth of second child and its correlation with selected demographic variable.

The study was based on the fact that sibling rivalry is a natural and normal phenomenon.

The conceptual frame work of the present study was based on the attachment theory by John Bowlby,and it deals with the positive and negative behavioral changes in the child when there is loss or decrease in the love, care and emotional attachment. 


\section{International Journal of Science and Research (IJSR) \\ ISSN (Online): 2319-7064}

Index Copernicus Value (2013): 6.14 | Impact Factor (2014): 5.611

Non experimental convenient sampling was the good research design for the present study. Sample size selected for this study was 100 . Only those who fulfilled the sampling criteria and who expressed the willingness to participate in the study were selected for the study.

Development of tool involved the steps of reviewing literature related to firstborn child, second child and behavioral changes of firstborn after the birth of second child. Various experts validated the tool. The language expert translated the tool to Marathi. Pilot study was done and the same tool was used for the final study.

Based on the objectives the data was analyzed using inferential and descriptive ststistics. Chie-square was used to correlate the demographic variables.

Sibling rivalry is a universal problem. Every family complains of sibling rivalry between their sons and daughters. Each people feel it or experience it differently. The present study tries to find out the common behavioral changes in the firstborn child after the birth of second child.

The reliability co-efficient was done using test-re test method and was found to be 0.92 .The research design used was the non-experimental exploratory survey research design. Nonprobability convenient sampling method was used .100 mothers was selected according to the criteria.

\section{Conclusion}

Children are the gift of God, a precious treasure natured with love and care. Many kids are lucky enough to become the best of friends with their siblings, though it was very common for brothers and sisters to fight. The studies so far indicate that most occurrences of regressive and aggressive behaviors are mild to moderate and to be expected and it is a part of normal growth and development. The present study reveals that majority of the first born children were having moderate degree of sibling rivalry. Only minimum (13\%) shows that there is severe sibling rivalry between firstborn and secondborn child. It was observed that when the spacing between two children decreases the sibling rivalry increases.

\section{Implications}

The findings of the study will help nurses in the following aspects:-

\section{Education}

1. To evaluate mental heath status of children which could be affected by the sibling rivalry

2. To make the mothers aware of the normal sibling rivalry among their children.

3. To educate the parents about the normal behavior in sibling rivalry.

4. To make the children aware of the normal behavior in sibling rivalry

5. To communicate these findings to pediatric society, connecting centers.

6. To communicate these study findings to the counselors, pediatric nurses to utilize them during the guidance sessions.

\section{Nursing Practice}

Nursing education is developing rapidly in India and nurse from our country can be found all over the world providing care and education.

The education curriculum must include imparting knowledge about the use of various teaching strategies for heath education.

Now a day much importance is given to awareness and promotion of health than the curative aspects. As the needs of the society are continuously changing, newer components must be incorporated in the nursing curriculum. Nursing education must emphasize on preventive aspects of health.

The nursing teachers can use the result of the study as an informative illustration for the students.

To make the students aware of the changing trends in the society with increasing pressure on siblings to out perform each other as nurses we should be able to handle such children and be able to provide care.

Nurses can encourage pediatric clients to verbalize their concerns, with guidance and counseling and this should be introduced in the curriculum.

Nurses would be able to evaluate the future health problems associate with sibling rivalry at an earlier age.

\section{Nursing Administration}

As part of administration, nurse administrator plays a vital role in the education of all the nurses. The findings of the study should be used as a basis of in-service education programs for nurses so as to make them aware of the problems in the children \& communicate the findings to guidance and counseling centers and the parents so that they could take appropriate steps in treating it at an earlier stage.

\section{Nursing Research}

Nursing research is an essential aspect of nursing education as it uplifts the profession, develops new nursing norms and enhances the body of nursing knowledge. It also improves the image and perception of nursing in society, which is urgently required for the future of nursing.

\section{Limitations of the Study}

1) Mothers were not comfortable in answering question, which not would expose the actual behavior of her child.

2) Depends upon the recall capacity or memory of the mother.

3) Limited period of time for study.

4) The study is limited to the experience level of the investigator.

\section{Recommendations of the Study}

1) A similar study can be conducted on a larger population for better generalization of findings.

2) A similar study can be conducted using observational checklist. 
3) A comparative study can be conducted to assess the behavioral changes observed in the firstborn child in rural and urban area.

4) A similar study can be conducted to assess the problems faced by mother to adjust with two children when firstborn child has behavioral problems.

\section{References}

[1] KidsHealthhttp://kidshealth.org/parent/emotions/feelings /sibling_rivalry.html

[2] Steven Parken and Barry ukkerman(2005),Developmental and behavioral paediatrics,Lippincott,p-412-414.

[3] Smith et.el(1991), Comprehensive child and Family nursing Skills,Mosby year book,p-94-95.

[4] Caroll.[2000].Contemporary Psychiatric mental health Nursing,the brain and behaviour connection, F A Davis Company.Philadelphia.P-432

[5] Carol Tayler.(1993).Fundamentals of Nursing, The art and science of Nursing care(P.397-398).Philadelphia: Lippincott

[6] Canadian Pediatric Society www.caringforkinds.cps.ca

[7] Dean Fowler and Peg Masterson edquist(feb.2004),Sibling Rivalry can destroy family business, the business Journal.

[8] SHINDE, M., \& ANJUM, S. (2007). Introduction to Research In Nursing.Sneha Publication India (Dombivili).

[9] www.emedicine.com

[10]Dr.Mahinder Wasta,Pune mirror,Times of ndia,May8\&August $12^{\text {th }} 2008$.

[11]B.T Basavantappa.[2005]Pediatric/ child heath Nursing. First edition.Ahuja Publishing house.P-314

[12] http;//wwwBoloji.com/parenting/02297.htm

\section{Author Profile}

Shaila Mathew is Lecturer Bharati Vidyapeet College of Nursing, Sangli

Ranjana G.Tryambake is Lecturer Bharati Vidyapeet College of Nursing, Pune. 